\title{
The role of MglA for adaptation to oxidative stress of Francisella tularensis LVS
}

\author{
Marie Honn, Helena Lindgren and Anders Sjöstedt ${ }^{*}$
}

\begin{abstract}
Background: The Francisella tularensis protein MglA performs complex regulatory functions since it influences the expression of more than 100 genes and proteins in F. tularensis. Besides regulating the igl operon, it has been suggested that it also regulates several factors such as SspA, Hfa, CspC, and UspA, all important to stress adaptation. Therefore, it can be hypothesized that MgIA plays an important role for Francisella stress responses in general and for the oxidative stress response specifically.

Results: We investigated the oxidative stress response of the $\triangle m$ IIA mutant of the live vaccine strain (LVS) of $F$. tularensis and found that it showed markedly diminished growth and contained more oxidized proteins than the parental LVS strain when grown in an aerobic milieu but not when grown microaerobically. Moreover, the $\triangle m g / A$ mutant exhibited an increased catalase activity and reduced expression of the $f_{s} /$ operon and $f e o B$ in the aerobic milieu. The mutant was also found to be less susceptible to $\mathrm{H}_{2} \mathrm{O}_{2}$. The aberrant catalase activity and gene expression was partially normalized when the $\triangle m g / A$ mutant was grown in a microaerobic milieu.

Conclusions: Altogether the results show that the $\triangle m g / A$ mutant exhibits all the hallmarks of a bacterium subjected to oxidative stress under aerobic conditions, indicating that MglA is required for normal adaptation of $F$. tularensis to oxidative stress and oxygen-rich environments.
\end{abstract}

\section{Background}

Francisella tularensis is a facultative intracellular, gramnegative coccobacillus, which causes the potentially lethal disease tularemia. This zoonotic disease is transmitted via vectors such as ticks and mosquitoes and infects predominantly mammals such as small rodents, hares and rabbits [1]. The subspecies tularensis and holarctica also give rise to human infections. The pathogen is highly contagious, requiring as few as 10 bacteria to cause human infection, and subspecies tularensis causes a very aggressive disease with high mortality in humans if untreated [2]. The high virulence, ease of spread, and potentially high mortality of tularemia has led to the classification of $F$. tularensis as one of six category A select agents, i.e., the agents most likely to be used for bioterrorism [3]. In experimental infections, F. novicida and F. tularensis LVS are often used since both show significant virulence in small rodents but still

\footnotetext{
* Correspondence: Anders.sjostedt@climi.umu.se Department of Clinical Microbiology, Clinical Bacteriology, and Laboratory for Molecular Infection Medicine Sweden (MIMS), Umeå University, 90185 Umeå, Sweden
}

( 2011 Honn et al; licensee BioMed Central Ltd. This is an Open Access article distributed under the terms of the Creative Commons Attribution License (http://creativecommons.org/licenses/by/2.0), which permits unrestricted use, distribution, and reproduction in any medium, provided the original work is properly cited. are classified as BSL2 pathogens. The former species very rarely causes human infections and the latter is a human vaccine strain of subspecies holarctica origin [4].

An important virulence trait of $F$. tularensis is its ability to survive and multiply in an array of different cell types including hepatocytes and professional phagocytes [5]. The intracellular lifestyle relies on escape from the phagosome and the subsequent proliferation in the cytoplasm [6]. The mechanism of escape from the phagosome is not known but requires expression of the global regulator MglA (macrophage growth locus) [7]. This is most likely through its positive regulation of the genes belonging to the intracellular growth locus $(i g l)$ and other genes of the Francisella pathogenicity island. MglA together with an ortholog, SspA, forms a complex that directly interacts with the RNA polymerase [8] conferring a complex regulatory role that leads to the control of more than 100 genes and proteins in $F$. tularensis $[9,10]$. Besides the igl operon, it has been suggested that the activities of several stress-regulated factors, such as SspA, Hfq, CspC, and UspA, are linked to the MglA-dependent regulation [10]. Thereby, it plays 
an important role for the intracellular growth and stress responses in general and for the adaptation to oxidative stress response specifically.

Iron is essential for the survival of almost all living organisms. Limiting the amount of iron accessible to pathogens is therefore an important part of the host defence system [11]. Thus, it is essential for successful pathogens to circumvent this and they have evolved various strategies, such as the usage of siderophores, which are high affinity iron chelators synthesized in response to iron starvation [12]. Siderophore production in Francisella is dependent on proteins encoded in the $f_{s} l$ operon (Francisella siderophore locus) [13-15]. Besides the $f s l$ operon, the ferrous iron transport protein FeoB may contribute to the iron sequestration in F. tularensis. Similar to most other genes related to iron uptake in bacteria, the $f_{s} l$ operon and $f e o B$ are under the negative control of Fur $[[15,16]$; Honn et al., unpublished]. When sufficient iron is available, Fur binds to a Fur box and thereby suppresses gene expression, whereas under low iron concentrations, Fur is released and transcription resumes. The iron uptake by the pathogens has to be fine-tuned since an excess of iron could be detrimental by potentiating the toxicity of $\mathrm{H}_{2} \mathrm{O}_{2}$ through the Fenton reaction, which generates highly reactive hydroxyl radicals and anions [17]. In fact, regulation of iron uptake, and oxidative stress are intimately linked, as evidenced by the regulation of iron uptake-related genes in, e.g., Escherichia coli. In this bacterium, oxyR is activated by $\mathrm{H}_{2} \mathrm{O}_{2}$ and causes an upregulation of Fur and catalase expression and this reduces the concentration of iron and $\mathrm{H}_{2} \mathrm{O}_{2}$ and thereby diminishes the Fenton reaction [18].

In the present study, we investigated how the $\Delta m g l A$ mutant of LVS coped with oxidative stress. To this end, the accumulation of oxidized proteins in LVS and $\Delta m g l A$ during growth was assessed and it was further tested if growth under microaerobic conditions affected oxidative stress parameters.

\section{Material and methods}

\section{Bacterial strains}

Francisella tularensis LVS, FSC155, was obtained from the American Type Culture Collection (ATCC 29684). The $\Delta m g l A$ mutant of LVS has been described previously $[7,19]$. For complementation in trans, the intact $m g l A$ gene was amplified by PCR and cloned to pKK289Km [20], resulting in plasmid pKK289Km mglA. The resulting plasmid was then introduced into $\Delta m g l A$ by cryotransformation and the resulting strain designated FUU301. The katG mutant has been previously described [21].

\section{Growth experiments}

For liquid cultures, the F. tularensis strains were placed on McLeod agar plates (MC plates) that were incubated overnight under aerobic $\left(20 \% \mathrm{O}_{2}+0.05 \% \mathrm{CO}_{2}\right)$ or microaerobic condition $\left(10 \% \mathrm{O}_{2}+10 \% \mathrm{CO}_{2}\right)$ in an incubator with $\mathrm{O}_{2}+\mathrm{CO}_{2}$ control (Sanyo, Loughborough, UK). Bacteria from these plates were suspended in the Chamberlain's chemically defined medium (CDM), or in iron-depleted CDM (C-CDM), to an optical density at $\mathrm{A}_{600} \mathrm{~nm}\left(\mathrm{OD}_{600}\right)$ of $\approx 0.15$. The latter media was used for depletion of the internal iron pool of the bacteria and was prepared as described previously [22]. The cultures were incubated overnight at $37^{\circ} \mathrm{C}$ and a rotation of $200 \mathrm{rpm}$ under aerobic or microaerobic conditions. Thereafter, cultures were diluted in fresh CDM to an $\mathrm{OD}_{600}$ of 0.2 and cultivated as described above in the respective milieu. Iron-depleted bacteria were diluted in $\mathrm{C}$-CDM to which 1,000 ng/ml FeSO4 had been added. Dilution and handling of the bacteria during the experiment were performed aerobically. Samples from these cultures were used to measure the levels of oxidized proteins, catalase activity, iron pool, gene expression and susceptibility to $\mathrm{H}_{2} \mathrm{O}_{2}$ of the bacteria.

For growth test on solid medium, the $F$. tularensis strains were richly streaked on MC plates that were incubated in $37^{\circ} \mathrm{C}$ and $5 \% \mathrm{CO}_{2}$ over night. Bacteria were harvested, serially diluted in PBS and $100 \mu \mathrm{l}$ of a dilution estimated to give approximately 100 colony forming units per plate were evenly spread on MC plates. The plates were incubated at $37^{\circ} \mathrm{C}$ in an aerobic or microaerobic milieu and the colony size scored after 2,3 , and 6 days of incubation.

\section{OxyBlot assay}

The OxyBlot Protein Oxidation Detection Kit (Chemicon International) is based on a method for detection of carbonyl groups introduced into proteins by oxidative reactions. The carbonyl groups are derivatized to 2,4dinitrophenylhydrazone (DNP-hydrazone) by use of 2,4dinitrophenylhydrazine (DNPH) and can thereafter be detected by immunostaining. The OxyBlot kit was used to compare the amount of oxidized proteins in LVS and $\Delta m g l A$ grown in an aerobic or a microaerobic milieu. Samples were collected at an $\mathrm{OD}_{600}$ of 0.6-0.7 and the bacteria were lysed using a buffer containing $2 \mathrm{M}$ thiourea, $7 \mathrm{M}$ urea, 4\% CHAPS (3-[(3-Cholamidopropyl) dimethylammonio]-1-propanesulfonate), 0.5\% ASB-14 (amidosulfobetaine-14), 1.0\% DTT, $0.5 \times$ protease inhibitor, and $1 \% \beta$-mercaptoethanol. The amounts of protein in the samples were determined by use of the Bradford assay (Fermentas, St. Leon-Rot, Germany). The assay was carried out according to the manufacturer's protocol for Standard Bradford assay in microplates. 
Equal amounts of proteins were taken from each sample for derivatization and synthesis of negative controls according to the manufacturer's protocol. Briefly, samples were incubated with $1 \times \mathrm{DNPH}$ solution for $15 \mathrm{~min}$ at RT to allow derivatization of carbonyl-groups to DNP-hydrazone, after which a neutralization solution was added. Negative controls were prepared as the samples with the exception that they were treated with $\mathrm{dH}_{2} \mathrm{O}$ instead of $1 \times \mathrm{DNPH}$ solution, and therefore lack DNP-hydrazone. Negative controls were synthesized in order to ensure the specificity of the antibodies used for detection of DNP-moieties in oxidized proteins. Samples were blotted to PVDF membranes using a Bio-Dot Microfiltration Apparatus (BioRad), immunostained using a primary Rabbit anti-DNP antibody and a secondary Goat Anti-Rabbit IgG (HRP-conjugated) antibody; and developed with chemiluminescence to visualize the DNP-modifications, as directed by the instructions provided in the OxyBlot Kit. Samples were blotted at a concentration of $2.5 \mathrm{ng}$ of protein in the first well followed by two-fold dilutions thereof.

\section{Catalase assay}

LVS and $\triangle m g l A$ were cultivated overnight in CDM and thereafter sub-cultured in CDM. When bacteria reached logarithmic growth phase (0.4-0.7 $\left.\mathrm{OD}_{600} \mathrm{~nm}\right)$, the $\mathrm{OD}_{600}$ of the cultures were measured and 20-50 $\mu \mathrm{l}$ of culture was withdrawn and transferred to a 96-well UVclear plate (Greiner Bio-One, Frickenhausen, Germany). To each well, PBS was added to give a final volume of $200 \mu \mathrm{l}$. Finally, $80 \mu \mathrm{l}$ of $100 \mathrm{mM} \mathrm{H}_{2} \mathrm{O}_{2}$ in PBS was added to start the reaction. The decomposition of $\mathrm{H}_{2} \mathrm{O}_{2}$ was measured by monitoring the decrease in absorbance at $240 \mathrm{~nm}$ using a microplate reader (Paradigm, Beckman Coulter). Each strain was run in five replicates. The initial linear portion of the curve was used to calculate the $\Delta 240 \mathrm{~nm}$. A molar extinction coefficient of $\mathrm{H}_{2} \mathrm{O}_{2}$ at $240 \mathrm{~nm}$ of $43.6 \mathrm{M}^{-1} \mathrm{~cm}^{-1}$ was used to calculated the concentration of $\mathrm{H}_{2} \mathrm{O}_{2}$ using the Beer-Lambert law, $A=$ $\varepsilon c l$. One unit of catalase was defined as the amount that decomposes $1 \mu \mathrm{mol}$ of $\mathrm{H}_{2} \mathrm{O}_{2}$ per minute per $\mathrm{OD}_{600}$ at $25^{\circ} \mathrm{C}$.

\section{Analysis of gene expression}

Bacteria were collected from cultures after $18 \mathrm{~h}$ of incubation and mixed with 50\% (v/v) RNAlater (Qiagen, Hilden, Germany) and when needed, placed in $-20^{\circ} \mathrm{C}$, to stabilize the RNA until extraction could be performed. RNA was extracted using Trizol (Invitrogen) according to the manufacturer's protocol. cDNA was synthesized from this RNA and quantitative real-time PCR (RTPCR) was used to analyze the cDNA samples. In order to remove contaminating DNA, the RNA samples were
DNase-treated (DNA-free kit, Ambion, Inc, Austin, TX, USA) in accordance with the protocol supplied by the manufacturer. The RNA was quantified by Nanodrop (Thermo Fisher Scientific, Wilmington, DE, USA). cDNA was synthesized from $1 \mu \mathrm{g}$ of the extracted RNA using iScript cDNA synthesis kit (Bio-Rad, Hemel, Hampstead, UK) according to the protocol provided by the manufacturer. To control for contaminating DNA in the RNA preparation, a control was prepared by substituting the enzyme from the cDNA synthesis for nuclease-free $\mathrm{H}_{2} \mathrm{O}$ (Ambion) (control 1). In order to degrade any remaining RNA, the cDNA was treated with $2.0 \mu \mathrm{l}$ of $2.5 \mathrm{M} \mathrm{NaOH}$ at $42^{\circ} \mathrm{C}$ for 10 minutes after which the $\mathrm{pH}$ was adjusted by the addition of $5 \mu \mathrm{l}$ of $1 \mathrm{M} \mathrm{HCl}$. The samples were thereafter diluted and stored at $-20^{\circ} \mathrm{C}$.

RT-PCR was performed in the ABI Prism $7900 \mathrm{HT}$ Sequence Detection System (Applied Biosystems, Foster City, CA, USA) using the Power SYBR green PCR Master Mix (Applied Biosystems) as recommended by the manufacturer. Each reaction contained $12.5 \mu \mathrm{l}$ of the SYBR green mix, $400 \mathrm{nM}$ of forward and reverse primers, $5 \mu \mathrm{l}$ of a cDNA and the total volume was adjusted with nuclease free water to $25 \mu \mathrm{l}$. Forward and reverse primers were obtained from Invitrogen and their sequences have been previously published [20,23] with the exception of the pairs used to measure $\operatorname{mgl}$, feoB and $k a t G$. The sequences for $m g l A$ were the following: FTT1275-F, 5'-TTG CAG TGT ATA GGC TTA GTG TGA-3' and FTT1275-R, 5'-ATA TTC TTG CAT TAG CTC GCT GT-3', for feoB: FTT0249-F, 5'-TCA CAA GAA ATC ACA GCT AGT CAA-3' and FTT0249-R, 5'-CTA CAA TTT CAG CGA CAG CAT TAT-3' and for katG the following: FTT0721c-F, 5'-TTC AAG TTT AGC TGG TTC ATT CAT-3'and FTT0721c-R, 5'-GCT TGG GAT TCA GCT TCT ACT TAT-3'. The reactions were performed in MicroAmp 96-well plates (Applied Biosystems). The reactions were incubated at $50^{\circ} \mathrm{C}$ for 2 $\min , 10 \mathrm{~min}$ at $95^{\circ} \mathrm{C}$ followed by 45 cycles of $15 \mathrm{~s}$ at $95^{\circ}$ $\mathrm{C}$ and $1 \mathrm{~min}$ at $60^{\circ} \mathrm{C}$ and a final cycle consisting of incubation at $95^{\circ} \mathrm{C}$ for $15 \mathrm{~s}, 60^{\circ} \mathrm{C}$ for $15 \mathrm{~s}$, and at $95^{\circ} \mathrm{C}$ for 15 s. The lowest dilution that allowed detection of the gene within the linear working range was chosen as the dilution to be used for the analysis of the genes of interest. To control for contaminating DNA in the reaction, tubes with template from control 1 (see above) and tubes with water instead of template were included in the analysis. The controls gave $\mathrm{Ct}$ values $(\mathrm{Ct}$ is the threshold cycle) below detection level or at least 8 cycles later than the corresponding cDNA. Relative copy numbers $(\mathrm{RCN})$ of selected genes were expressed in relation to the expression of the housekeeping gene tul4 [24] and calculated according to the following equation: $\mathrm{RCN}=2^{-} \Delta^{\mathrm{Ct}} \times 100$ where $\Delta \mathrm{Ct}$ is $\mathrm{Ct}$ (target) $-\mathrm{Ct}_{(t u l 4)}$ 
[25]. Thus, the copy number of a given gene is related to the copy number of tul4. Normalized Ct-values were used for statistical evaluation of the data.

\section{Chromazurol-S (CAS) plate assay}

Chrome-azurol sulfonate-C-CDM agar plates (CAS plates) were prepared essentially as described [13]. Briefly, $40 \mathrm{ml}$ of CAS/Fe(III)-hexadecyltrimethylammonium solution was mixed with $50 \mathrm{ml}$ of a $4 \%$ (wt/vol) solution of GC II Agar Base (BD Diagnostic Systems, Franklin Lakes, NJ, USA) and $110 \mathrm{ml}$ of C-CDM. The resulting CAS-C-CDM agar solution (1\% agar) was poured into $20 \mathrm{ml}$ Petri dishes. All components of the CAS-solution were purchased from Sigma-Aldrich, Buchs, Switzerland.

Bacteria were cultivated overnight in C-CDM and thereafter washed three times in C-CDM before dilution in $\mathrm{C}-\mathrm{CDM}$ to $1.0 \mathrm{OD}_{600}$. The suspension was added as a droplet of $2.5 \mu \mathrm{l}$ to the center of the CAS plate. The plates were incubated at $37^{\circ} \mathrm{C}$ in $5 \% \mathrm{CO}_{2}$ and the size and appearance of the halo formed around the bacterial colony was scored at $72 \mathrm{~h}$.

\section{Ferrozine assay}

A ferrozine-based method was used to measure the total amount of iron in the bacterial samples and in culture medium [26]. Ferrozine forms a complex with $\mathrm{Fe}^{2+}$ that absorbs light at $562 \mathrm{~nm}$. To determine the iron content of bacteria, a volume corresponding to $1.0 \mathrm{OD}_{600}$ was withdrawn from the culture and bacteria collected by centrifugation for $5 \mathrm{~min}$ at 13,000 rpm. The bacteria were resuspended in PBS and collected by centrifugation. The resulting bacterial pellet was lysed with $100 \mu \mathrm{l}$ of $50 \mathrm{mM} \mathrm{NaOH}$. The solution was mixed thoroughly to ensure complete lysis of the bacteria. One hundred $\mu \mathrm{l}$ of $10 \mathrm{mM} \mathrm{HCl}$ was added to the lysate. To release protein-bound iron, the samples were treated with $100 \mu \mathrm{l}$ of a freshly prepared solution of $0.7 \mathrm{M} \mathrm{HCl}$ and $2.25 \%$ (w/ v) $\mathrm{KMnO}_{4}$ in $\mathrm{H}_{2} \mathrm{O}$ and incubated for $2 \mathrm{~h}$ at $60^{\circ} \mathrm{C}$. All chemicals used were from Sigma-Aldrich. Thereafter, the samples were mixed with $100 \mu \mathrm{l}$ of the iron detection reagent composed of $6.5 \mathrm{mM}$ ferrozine, $6.5 \mathrm{mM}$ neocuproine, $2.5 \mathrm{M}$ ammonium acetate, and $1.0 \mathrm{M}$ ascorbic acid dissolved in water. For determination of iron in medium, $30 \mu \mathrm{l}$ of iron detection reagent was mixed with $170 \mu \mathrm{l}$ of bacterial-free culture medium. The bacterial and medium samples were incubated with the iron-detection reagent for $30 \mathrm{~min}$ and insoluble particles were removed by centrifugation. Two hundred $\mu \mathrm{l}$ of the supernatant was transferred to a 96-well plate and the $\mathrm{A}_{562}$ determined in a microplate reader (Paradigm, Beckman Coulter, Bromma, Sweden). The iron content of the sample was calculated by comparing its absorbance to that of samples with $\mathrm{FeCl}_{3}$ concentrations in the range of $0-5,000 \mathrm{ng} / \mathrm{ml}$ that had been prepared identically to the test samples. The correlation coefficients of the standard curves varied between 0.998 and 0.999 . The detection limit of the assay was $50 \mathrm{ng} / \mathrm{ml}$ Fe. The intrasample variations (i.e., samples from the same culture) were less than $17 \mathrm{ng} / \mathrm{OD}_{600}$.

\section{$\mathrm{H}_{2} \mathrm{O}_{2}$ susceptibility test}

Bacteria were cultivated overnight in CDM and thereafter cultured in fresh $\mathrm{CDM}$ for $2 \mathrm{~h}$ at $37^{\circ} \mathrm{C}$ and 200 rpm. The density of the cultures was measured and cultures were serially diluted in PBS to approximately $10^{6}$ bacteria per $\mathrm{ml}$. The exact number of bacteria at the start of the experiment was determined by viable count. The bacterial suspension was divided in $2 \mathrm{ml}$ aliquots in $10 \mathrm{ml}$ screw cap tubes. To some tubes $\mathrm{H}_{2} \mathrm{O}_{2}$ (Sigma) was supplied to reach a final concentration of $0.1 \mathrm{mM}$ and other tubes were left untreated as controls. The tubes were incubated at $37^{\circ} \mathrm{C} 200 \mathrm{rpm}$. After 0 and $2 \mathrm{~h}$ of incubation, bacterial samples were collected and viable bacteria determined by plating 10 -fold serial dilutions. The plates were incubated for 3 days at $37^{\circ} \mathrm{C} 5 \%$ $\mathrm{CO}_{2}$ before enumeration of the colony forming units (CFU).

\section{Statistical analysis}

For statistical evaluation, two-tailed Student's $t$-test and two-tailed Pearson's correlation test in the statistical software program SPSS, version 16 were used.

\section{Results}

\section{Growth of LVS and $\Delta m g I A$ under aerobic or microaerobic} conditions

CDM is a liquid medium that effectively supports growth of $F$. tularensis. Accordingly, LVS grew to an $\mathrm{OD}_{600}$ of approximately 3.0 within $24 \mathrm{~h}$ under aerobic conditions, however, $\Delta m g l A$ reached an $\mathrm{OD}_{600}$ of only slightly above 1.0 (Figure 1). In some experiments, LVS grew as well under microaerobic and aerobic conditions, but in other experiments, the growth was slightly reduced under the former condition (Figure 1). $\Delta m g l A$ grew as well in the microaerobic as in the aerobic milieu during the first hours, but after approximately $24 \mathrm{~h}$, its growth rate was reduced in the aerobic milieu, whereas it reached the same density as LVS in the microaerobic milieu after $48 \mathrm{~h}$ (Figure 1). FUU301 ( $\Delta m g l A$ expressing $m g l A$ in trans) exhibited an intermediary growth in the aerobic milieu and its density was $2.09 \pm 0.05$ vs. $2.59 \pm$ 0.05 for LVS, whereas growth of the two strains was similar in the microaerobic milieu.

It was also tested if the growth of LVS and $\triangle m g l A$ on solid medium was affected by the oxygen concentration. Approximately 100 bacteria were spread onto agar plates that were incubated in an aerobic or a 


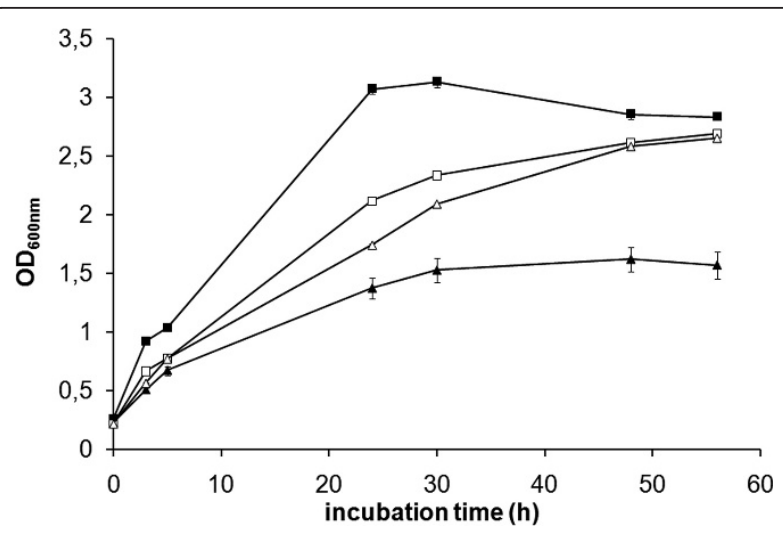

Figure 1 Growth of LVS (squares) and $\Delta m g I A$ (triangles) in CDM in an aerobic (closed symbols) or microaerobic (open symbols) milieu. The diagram shows one representative experiment and similar results were seen in three additional experiments. The error bars represent the standard error of means and are included for all strains but are small for some data points and are therefore not visible in the diagram.

microaerobic milieu. LVS formed colonies $>$ two $\mathrm{mm}$ in size in both environments within 6 days but with delayed kinetics aerobically (Table 1 ). $\Delta m g l A$ formed only few and small colonies on plates incubated aerobically. In the microaerobic milieu, however, it formed colonies of the same size as LVS, but with slightly delayed kinetics. Thus, regardless of growth medium used, $\Delta m g l A$ appeared to exhibit markedly impaired growth under aerobic conditions.

\section{Oxidized proteins in LVS and $\triangle m g / A$ cultivated under aerobic or microaerobic conditions}

We hypothesized that the aberrant oxidative stress response of $\triangle m g l A$ reported previously $[8,10]$ may lead to suboptimal handling of the effects of oxidation. We therefore attempted to quantify such effects at a more general level. To this end, we analyzed the presence of oxidized proteins using the OxyBlot method. Preparations from $\triangle m g l A$ cultivated under the aerobic conditions contained significantly more oxidized proteins

Table 1 Size of colonies formed by LVS and $\Delta m g I A$ on agar plates under aerobic or microaerobic conditions

\begin{tabular}{ccccc}
\hline \multirow{2}{*}{ Incubation time (days) } & \multicolumn{4}{c}{ Colony size $^{\text {a }}$} \\
\cline { 2 - 5 } & \multicolumn{2}{c}{ Aerobic } & \multicolumn{1}{c}{ Microaerobic } \\
\cline { 2 - 5 } & LVS & $\Delta m g l A$ & LVS & $\Delta m g I A$ \\
\hline 2 & 0 & 0 & 1 & 0 \\
3 & 1 & 0 & 2 & 1 \\
6 & 3 & MC $^{b}$ & 3 & 3 \\
\hline
\end{tabular}

\footnotetext{
${ }^{\text {a }}$ Colony size was graded as follows: $0=$ Not visible, $1=$ colonies $<1 \mathrm{~mm}$ in diameter, $2=1.0-2.0 \mathrm{~mm} .3=>2 \mathrm{~mm}$ in diameter

${ }^{b}$ Mixed colonies, a few large colonies growing in close proximity to each other but most colonies were hardly visible
}

than did those prepared from LVS (Figure 2). In contrast, the amounts of oxidized proteins were similar after cultivation in the microaerobic milieu. We noted some inter-experimental variation, but there were markedly increased amounts of oxidized proteins in the $\Delta m g l A$ preparations under aerobic conditions in a majority of the experiments performed. FUU301 contained similar amounts of oxidized proteins as LVS regardless of growth condition (Figure 2).

In summary, the marked accumulation of oxidized proteins in $\triangle m g l A$ during growth in the aerobic milieu strongly suggested that the mutant had an impaired response to oxidation. This may have been a reason for its delayed and lower maximal growth in the aerobic milieu.

\section{Catalase activity in LVS and $\Delta m g / A$ cultivated under aerobic or microaerobic conditions}

As judged from the levels of oxidized proteins, $\Delta m g l A$ experienced increased oxidative stress during growth in the aerobic milieu. E. coli responds to oxidative stress by upregulating the expression of catalase that degrades $\mathrm{H}_{2} \mathrm{O}_{2}$ and we asked if this was the case also for F. tularensis [18]. In addition, it has previously been demonstrated that the F. novicida $\triangle m g l A$ mutant shows higher catalase activity than does the wild-type [10]. The catalase activity of LVS and $\Delta m g l A$ was measured under aerobic and microaerobic conditions. The activity of LVS was similar under the two growth conditions, whereas $\triangle m g l A$ showed significantly lower activity under microaerobic conditions $(P<0.001)$ (Figure 3$)$. Still, $\triangle m g l A$ demonstrated an elevated activity relative to LVS even under microaerobic conditions $(P<0.02)$ and even more so under aerobic conditions $(P<0.001)$ (Figure 3). An LVS katG deletion mutant did not decompose any $\mathrm{H}_{2} \mathrm{O}_{2}$, confirming that the experimental protocol is appropriate for measuring catalase activity.

In summary, the catalase activity of $\triangle m g l A$ is strongly influenced by the oxygen concentration whereas no such correlation exists for LVS. This suggests that MglA is a factor that affects the regulation of the anti-oxidative response, particularly under aerobic conditions, and in its absence, the increased level of oxidation leads to a compensatory increase in the catalase activity.

\section{Regulation of the $f s l$ operon by LVS and $\Delta m g \mid A$}

Iron uptake is a factor that may be decreased by bacteria under oxidative stress in order to avoid toxic effects generated through the Fenton reaction [27]. Therefore, it would be logical if the iron regulation of $\triangle m g l A$ is affected by the oxidative stress that occurs during aerobic growth. To assess this, we measured the expression of genes of the $f s l$ operon and $f e o B$ by real-time PCR. Samples for the analysis were obtained after $18 \mathrm{~h}$ of 


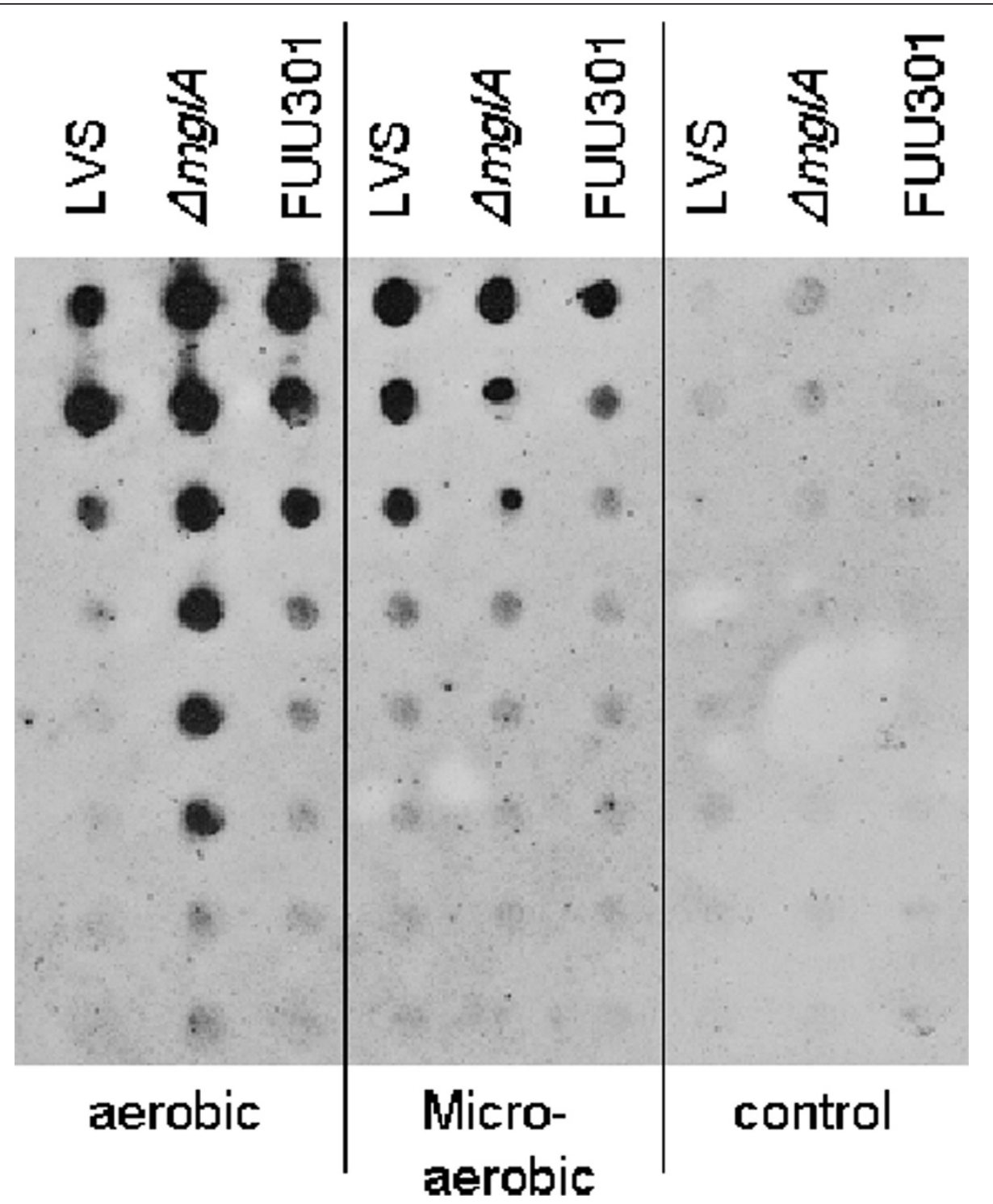

Figure 2 Analysis of oxidized proteins by the Oxyblot assay. Relative amounts of oxidized proteins in LVS, $\triangle m g / A$, or FUU301 during growth in an aerobic or microaerobic environment. Similar results were seen in two additional experiments. The first well of each preparation contained $2.5 \mathrm{ng}$ of protein and the following wells two-fold dilutions thereof. Controls contain non-derivatized samples, and demonstrate the specificity of the antibodies used for detection of oxidative damage.

growth, a time point when LVS had entered the stationary growth phase and the genes of the $f_{s} l$ operon were expected to be up-regulated due to iron deficiency.

In the aerobic milieu, LVS contained 4-12 fold more mRNA copies of $f_{s} l A-D$, 3.6-fold more copies of $f e o B(P$ $<0.001$ ), and 2-fold less copies of katG than did $\triangle m g l A$ $(P<0.05)$ (Table 2$)$. Notably, $f s l E$ was not differentially regulated (Table 2). As expected, expression of $i g l C$ was greatly suppressed in $\triangle m g l A$. Importantly, the expression of all genes except for $k a t G$ was restored to wildtype levels in the FUU301 strain when it was cultivated under aerobic conditions. FUU301 contained about 23- fold more mRNA copies of $m g l A$ than LVS. Notably, both LVS and FUU301 expressed significantly higher levels of $m g l A$ under microaerobic than aerobic conditions.

Compared to the aerobic conditions, LVS down-regulated $f s l A-D 2.5$-fold under microaerobic conditions, whereas, in contrast, $\triangle m g l A$ expressed 2-fold more of fs $l A-D$ microaerobically than aerobically. Overall, the adaptations under microaerobic conditions meant that $f_{s} l A-C$ and $f e o B$ were expressed slightly higher and $f_{s} l D$ and $f s l E$ almost 2-fold lower in LVS than $\triangle m g l A$ (Table $2)$. The $f_{s} l$ genes were expressed at similar levels, and 


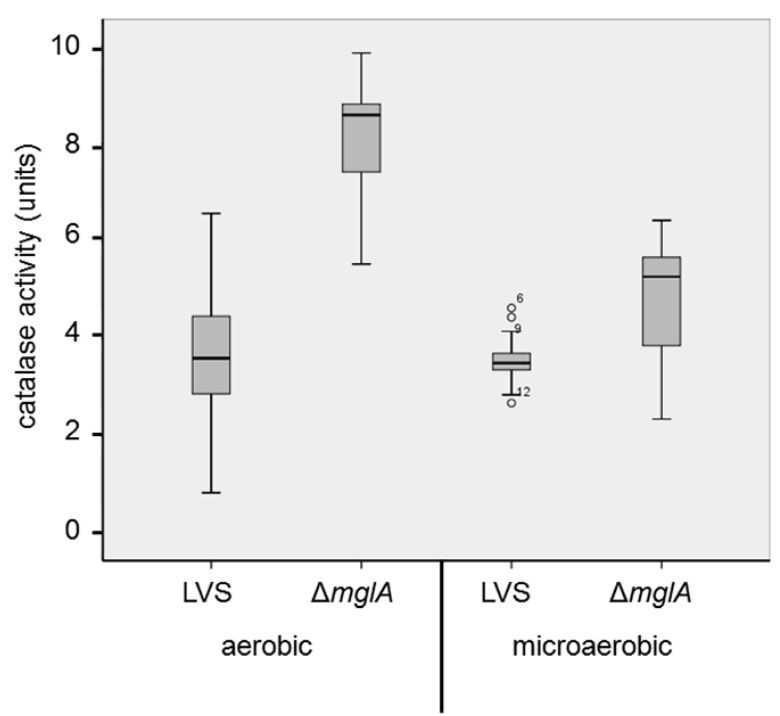

Figure 3 Catalase activity of LVS and $\mathbf{\Delta} \boldsymbol{m g} \mathbf{I}$. Samples from cultures that were in the logarithmic growth phase were analyzed by the catalase assay. The line through each box shows the median, with quartiles at either end of each box. The T-bars that extend from the boxes are called inner fences. These extend to 1.5 times the height of the box or, if no case has a value in that range, to the minimum or maximum values. The points are outliers. These are defined as values that do not fall within the inner fences

$f e o B$ was upregulated about 3-fold in FUU301 when cultivated in the microaerobic versus the aerobic milieu.

In summary, we observed that $\triangle m g l A$ very markedly down-regulated the $f s l A-D$ and $f e o B$ genes compared to LVS under aerobic conditions but that differences were only marginal microaerobically, despite that less iron was present when $\Delta m g l A$ had been cultivated under aerobic conditions. This supports our hypothesis that $\triangle m g l A$ is subjected to oxidative stress under aerobic conditions and therefore needs to minimize iron uptake

Table 2 Effect of growth condition on intra- and extra-cellular iron concentrations and gene regulation

\begin{tabular}{|c|c|c|c|c|c|c|}
\hline \multirow[t]{3}{*}{ Parameter tested } & \multicolumn{6}{|c|}{ Growth condition } \\
\hline & \multicolumn{3}{|c|}{ Aerobic } & \multicolumn{3}{|c|}{ Microaerobic } \\
\hline & LVS & $\Delta m g l A$ & FUU301 & LVS & $\Delta m g I A$ & FUU301 \\
\hline Fe intra ${ }^{a}$ & $626 \pm 27.2$ & $661 \pm 17.1$ & $643 \pm 24.5$ & $893 \pm 33.8$ & $589 \pm 21.9^{d}$ & $662 \pm 20.5^{d}$ \\
\hline \multirow[t]{2}{*}{ Fe extra ${ }^{b}$} & B.D.L. ${ }^{e}$ & $186 \pm 20.5$ & $64.5 \pm 8.97$ & $73.9 \pm 19.3$ & $327 \pm 10.7^{d}$ & $165 \pm 46.1$ \\
\hline & & & Gene regulation ${ }^{c}$ & & & \\
\hline$f_{S} / A$ & $12.7 \pm 0.64$ & $2.51 \pm 0.19^{f}$ & $10.6 \pm 1.33$ & $5.87 \pm 0.71$ & $4.93 \pm 0.48$ & $9.29 \pm 1.19^{9}$ \\
\hline$f_{S} \mid B$ & $6.27 \pm 0.39$ & $0.83 \pm 0.15^{f}$ & $5.6 \pm 1.09$ & $2.86 \pm 0.43$ & $1.87 \pm 0.30$ & $5.86 \pm 0.30$ \\
\hline$f_{S} / C$ & $5.96 \pm 0.36$ & $0.74 \pm 0.15^{f}$ & $4.86 \pm 0.68$ & $2.61 \pm 0.33$ & $1.55 \pm 0.28^{9}$ & $4.69 \pm 0.26^{9}$ \\
\hline$f_{s} \mid D$ & $3.19 \pm 0.23$ & $0.97 \pm 0.15^{f}$ & $3.52 \pm 0.35$ & $1.60 \pm 0.23$ & $2.40 \pm 0.27^{9}$ & $3.73 \pm 0.37^{9}$ \\
\hline fSIE & $0.82 \pm 0.24$ & $1.11 \pm 0.15$ & $1.55 \pm 0.20^{h}$ & $1.04 \pm 0.06$ & $1.98 \pm 0.14^{d}$ & $5.43 \pm 1.20^{\mathrm{d}}$ \\
\hline$f e o B$ & $4.03 \pm 0.29$ & $1.37 \pm 0.15^{f}$ & $4.95 \pm 0.27$ & $5.50 \pm 0.41$ & $4.33 \pm 0.52$ & $12.8 \pm 3.77$ \\
\hline katG & $50.7 \pm 8.62$ & $110 \pm 15.3^{h}$ & $116 \pm 18.21^{\mathrm{h}}$ & $79.1 \pm 7.14$ & $120 \pm 19.3$ & $135 \pm 12.2 \mathrm{i}$ \\
\hline ig/C & $390 \pm 140$ & $24.6 \pm 5.37^{f}$ & $385 \pm 58$ & $685 \pm 159$ & $38.5 \pm 15.9^{d}$ & $478 \pm 120$ \\
\hline$m g / A$ & $16.5 \pm 5.77$ & B.D.L. & $384 \pm 138^{h}$ & $63.7 \pm 17$ & B.D.L. & $637 \pm 173^{9}$ \\
\hline
\end{tabular}

${ }^{\mathrm{a}}$ The intracellular iron pool $\left(\mathrm{ng} / \mathrm{OD}_{600} \mathrm{~nm}\right)$ of the strains after $18 \mathrm{~h}$ of growth

${ }^{\mathrm{b}}$ Iron $(\mathrm{ng} / \mathrm{ml})$ remaining in the culture medium after $18 \mathrm{~h}$ of growth

c The expression of the genes was analyzed by quantitative real-time PCR. Results are expressed as RCN means \pm SEM of results from four independent samples

${ }^{d} P<0.001$ relative to LVS in the microaerobic condition

e Below Detection Limit

${ }^{f} P<0.001$ relative to LVS in the aerobic condition

${ }^{g} P<0.05$ relative to LVS in the microaerobic condition

${ }^{\mathrm{h}} P<0.05$ relative to LVS in the aerobic condition

${ }^{i} P<0.01$ relative to LVS in the microaerobic condition 
as a compensatory mechanism to avoid toxic effects of the Fenton reaction. Expression of kat $G$ was higher by the complemented FUU301 strain than by LVS under aerobic conditions, indicating that the former, as the $\Delta m g l A$ mutant, may be experiencing a certain level of oxidative stress.

Iron consumption and storage of LVS, $\Delta m g$ IA and FUU301 The $f_{s} l$ genes and $f e o B$ are iron-regulated through Fur in F. tularensis [27]. Therefore, the expression of these genes may be a reflection of the iron content of the medium, or iron that is stored intracellularly and how these parameters correlate to each other. To assess this, these parameters were measured by the ferrozine assay. Importantly, the samples were obtained from the same cultures and time points as those analyzed by RT-PCR (Table 2).

The medium from aerobic and microaerobic $\Delta m g l A$ cultures contained about $25 \%$ and $45 \%$, respectively, of the iron initially supplied $(735 \mathrm{ng} / \mathrm{ml})$ (Table 2$)$. This was significantly higher than for LVS cultures $(P<0.001$ for both milieus). By use of Pearson's test it was found that for LVS there was no correlation between expression of $f S l A-E$ or $f e o B$ and the levels of iron remaining in the medium. For $\triangle m g l A$, medium from microaerobic cultures contained more iron than that from aerobic cultures $(P<0.001)$ (Table 2$)$ and there was a correlation between the expression of $f_{s} l A$ and $f e o B$ and the iron concentration of the medium $(P<0.05)$.

The iron pool of LVS was 1.4-fold higher in the microaerobic than in the aerobic milieu $(P<0.001)$ and there was a correlation between the expression of $f s l A-D$, but not $f s l E$ and $f e o B$, and the iron pool $(P<0.01)$. In contrast to LVS, the iron pool of $\triangle m g l A$ did not increase under the microaerobic conditions and there was no correlation between the expression of $f s l A-E$ or $f e o B$ and the iron pool. The FUU301 strain was partly complemented for iron acquisition and storage (Table 2).

In summary, the intracellular iron pool but not the extracellular iron of LVS cultures strongly correlated to the regulation of the $f s l$ operon. Thus, a low intracellular iron pool appears to be an important trigger of the expression of $f s l A-D$ in LVS. This correlation seemed not to exist in $\triangle m g l A$ under aerobic conditions since $\Delta m g l A$, despite a low intracellular iron pool, had a repressed expression of $f s l A-D$ and $f e o B$. The repressed expression of $f s l A-D$ and $f e o B$ was mitigated when $\triangle m g l A$ grew under the microaerobic conditions, although extracellular iron levels were higher.

\section{Siderophore production and gene regulation by iron- starved LVS and $\Delta m g I A$}

It was assessed if the suppressed expression of the $f_{s l}$, $i g l C$, and $f e o B$ genes in $\triangle m g l A$ in the aerobic milieu occurred also if the strains were subjected to iron deficiency. To this end, LVS and $\Delta m g l A$ were first cultivated in C-CDM to deplete their intracellular iron pool and thereafter cultured in C-CDM with $1,000 \mathrm{ng} / \mathrm{ml}$ of $\mathrm{FeSO}_{4}$. Under these conditions, expression of the $f_{s} l$ genes was similar in the two strains (Table 3).

The CAS plate assay is well-established for measurement of siderophore production in F. tularensis and we now used it to assess the siderophore production in $\Delta m g l A[13,20,28]$. We did not observe any significant difference between the mutant and LVS. However, it should be noted that minor differences with regard to the siderophore production may not be detected in the assay.

Together, the gene regulation of iron-starved bacteria and the CAS assay demonstrates that when subjected to severe iron-deficiency, $\Delta m g l A$ regulates the $f_{s} l$ operon and similarly to LVS and has the capacity to produce siderophores. Thus, it appears to have no inherent defects with regard to iron uptake.

\section{Hydrogen peroxide susceptibility of LVS and $\Delta m g I A$}

In view of the elevated catalase activity and aberrant iron uptake displayed by $\Delta m g l A$, we hypothesized that this would affect its susceptibility to $\mathrm{H}_{2} \mathrm{O}_{2}$. This was also the case since more than $2.0 \log 10$ of LVS was killed during a $2 \mathrm{~h}$ incubation period when exposed to $0.1 \mathrm{mM} \mathrm{H}_{2} \mathrm{O}_{2}$, whereas the viability of $\Delta m g l A$ decreased only $1.0 \log 10$ by this treatment $(P<0.01)$ (Figure 4$)$.

It was tested if growth in the microaerobic milieu, which diminished the catalase activity in $\Delta m g l A$ and enhanced the iron uptake in LVS, affected the susceptibility of the strains to $\mathrm{H}_{2} \mathrm{O}_{2}$. Both LVS and $\Delta m g l A$ were completely eradicated by a $2 \mathrm{~h}$ exposure to 0.1 $\mathrm{mM} \mathrm{H} \mathrm{H}_{2} \mathrm{O}_{2}$ (Figure 4). In conclusion, our results show that the $\triangle m g l A$ mutant compared to LVS displayed increased resistance to $\mathrm{H}_{2} \mathrm{O}_{2}$ under aerobic conditions

Table 3 Gene regulation of iron-depleted LVS and $\Delta m g I A$ grown under aerobic conditions

\begin{tabular}{ccc}
\hline Gene & \multicolumn{2}{c}{ Gene regulation $^{\mathbf{a}}$} \\
\cline { 2 - 3 } & LVS & $\Delta$ mglA \\
\hline$f_{s} / A$ & $31.2 \pm 13.5$ & $27.5 \pm 10.5$ \\
$f_{S} / B$ & $3.75 \pm 1.51$ & $8.17 \pm 4.03$ \\
$f s / C$ & $3.22 \pm 1.61$ & $6.33 \pm 3.83$ \\
$f s / D$ & $1.33 \pm 0.45$ & $2.07 \pm 0.87$ \\
$f s / E$ & $0.27 \pm 0.10$ & $0.30 \pm 0.13$ \\
$f e o B$ & $0.37 \pm 0.19$ & $0.46 \pm 0.27$ \\
ig/C & $428 \pm 161$ & $11.1 \pm 5.41$ \\
mg/A & $19.2 \pm 12.5$ & B.D.L. \\
\hline
\end{tabular}

a The expression of the genes was analyzed by quantitative real-time PCR. Results are expressed as RCN means \pm SEM of results three to five independent samples

b Below Detection Limit 


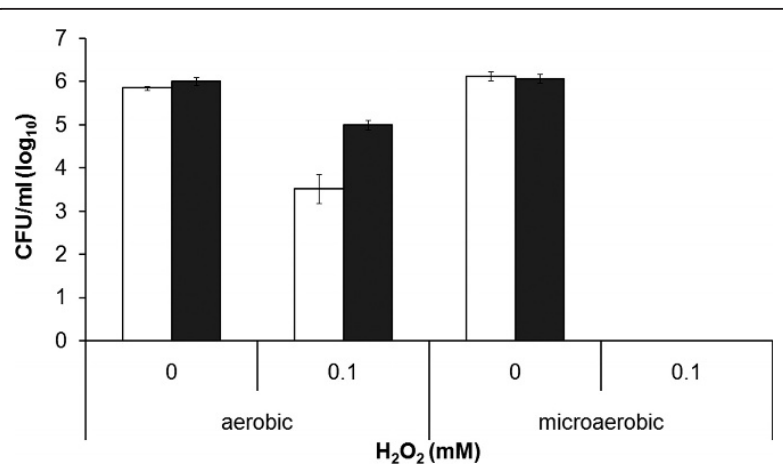

Figure 4 Survival of LVS (white bars) or $\Delta m g l A$ (black bars) after $2 \mathrm{~h}$ exposure to $\mathrm{H}_{2} \mathrm{O}_{2}$ Prior to the $\mathrm{H}_{2} \mathrm{O}_{2}$ challenge the bacteria had been cultivated for $2 \mathrm{~h}$ in CDM in the indicated milieu. The bars represent the average from four experiments with triplicate samples of each. The error bars indicate the SEM

whereas both showed markedly increased susceptibility to $\mathrm{H}_{2} \mathrm{O}_{2}$ under microaerobic conditions.

\section{Discussion}

It is well established that MglA plays an important role for the intracellular growth and virulence of $F$. tularensis, most likely through its regulation of genes of the $i g l$ operon and other genes of the Francisella Pathogenicity Island. There are also reports that MglA regulates the oxidative stress response in $F$. tularensis $[8,10]$ and that the $F$. novicida $m g l A$ mutant exhibits decreased survival during stationary-phase growth under nutrient-limiting conditions [10]. We observed that the LVS $\Delta m g l A$ mutant did not grow to high densities in a nutrient-rich medium and generated only small colonies on solid agar plates. Here we asked how the $m g l A$ deletion mutant of LVS handled oxidative stress and if an impaired adaptation is the basis for its inability to grow to high densities.

The results of the Oxyblot assay showed that the $\triangle m g l A$ mutant contained significantly more oxidized proteins than LVS under aerobic conditions. Reactive oxygen species are generated as a byproduct of the normal metabolism of a growing organism and there is, therefore, a continuous need to neutralize them to avoid oxidative damage of macromolecules in the cell. In view of this, the high level of oxidized proteins in $\Delta m g l A$ strongly suggests that MglA has a central role for the normal oxidative stress response and that its absence renders $F$. tularensis severely impaired to handle reactive oxygen species leading to specific protein damage which hampers the bacterial growth. In support of this, previously published data on the $F$. novicida $m g l A$ mutant revealed that key enzymes in the glutaredoxin systems, such as gluthathione synthetase, glutaredoxine, and thioredoxine, all of which have critical roles to neutralize reactive oxygen species [29], were greatly repressed $[9,10]$.

A rational adaptation to the increased oxidative stress encountered by $\triangle m g l A$ would be to decrease the irondriven Fenton reaction, which otherwise will result in the generation of highly reactive hydroxyl anions and radicals [17]. The most effective way to do this would be to limit the intracellular iron pool and upregulate the expression of catalase. Such an adaptation to oxidative stress has been noted in for example E. coli [18]. Our results support such a scenario also for $F$. tularensis since catalase was upregulated, thereby enhancing the capability of the bacterium to sustain an oxidative stress, and the expression of the $f s l$ operon and $f e o B$ was suppressed in $\triangle m g l A$ under aerobic conditions. Moreover, $\Delta m g l A$ regulated iron-uptake genes similarly to LVS under microaerobic conditions and under severe irondeprivation. This indicates that the marked downregulation of iron uptake genes observed under aerobic conditions does not relate to any inherent defects with regard to iron uptake, but instead is a compensatory mechanism needed to avoid the deleterious effects of the Fenton reaction.

An alternative explanation to the suppressed expression of the $f_{s l}$ operon and $f e o B$ in $\triangle m g l A$ could be high availability of iron in the medium. However, we found no correlation between iron content and the $f s l$ regulation, which further supports the hypothesis that oxidative stress was the primary reason for the dysregulation of the $f s l$ operon and $f e o B$ in $\Delta m g l A$ under aerobic conditions.

We hypothesized that the growth of $\Delta m g l A$ in the microaerobic milieu would reduce the oxidative stress. Indeed, the levels of oxidized proteins in the $\Delta m g l A$ mutant were normalized and similar to those found in LVS and, moreover, the growth of the mutant was similar to LVS. Other signs of reduced oxidative stress were the significantly reduced catalase activity and increased expression of the $f s l A-D$ and $f e o B$ genes. Collectively, all evidence indicates that MglA plays a critical role for the normal oxidative stress response and that its absence renders $F$. tularensis severely impaired to handle reactive oxygen species. We suggest that the lower levels of reactive oxygen species generated under growth in microaerobic conditions mitigated the defect of the mutant and, consequently, it grew as well as LVS under these conditions.

Our demonstration of an important role of MglA for the regulation of the $f s l$ operon and catalase are in agreement with two previous publications $[8,10]$, but if MglA directly regulates these genes is not known. Our present results suggest that the aberrant expression of catalase is an indirect effect of the increased oxidative stress of the $\triangle m g l A$ mutant since the catalase activity 
was normalized under the microaerobic conditions. Similarly, the mutant normalized expression of $f s l A-D$ and $f e o B$ under the microaerobic conditions and this also occurred under severe iron deficiency. In contrast, $i g l C$, known to be transcriptionally regulated by MglA, was repressed in $\triangle m g l A$ regardless of growth conditions or iron availability. Together these data imply that there are also MglA-independent mechanisms that transcriptionally regulate the $f s l, f e o B$ and $k a t G$ genes in $F$. tularensis.

The increased catalase activity in the $\Delta m g l A$ mutant is a likely explanation for the high resistance of the mutant to $\mathrm{H}_{2} \mathrm{O}_{2}$. Such a correlation was also reported for $F$. novicida [10]. Besides catalase, the size of the intracellular iron pool is a factor that determines the susceptibility of $F$. tularensis to $\mathrm{H}_{2} \mathrm{O}_{2}$ [22]. We recently showed that subspecies holarctica strains, including LVS, contain more iron and were more susceptible to $\mathrm{H}_{2} \mathrm{O}_{2}$ than strains of subspecies tularensis [22]. When the iron pool of the subspecies holarctica strains was depleted, their susceptibility to $\mathrm{H}_{2} \mathrm{O}_{2}$ decreased. Here we observed that LVS sequestered significantly more iron under the microaerobic conditions. Since iron is a factor that determines the susceptibility of $F$. tularensis to $\mathrm{H}_{2} \mathrm{O}_{2}$, it is very likely that the substantial iron pool of LVS under the microaerobic conditions contributed to its extreme susceptibility to $\mathrm{H}_{2} \mathrm{O}_{2}$. Iron could, however, not explain the high susceptibility of $\Delta m g l A$ to $\mathrm{H}_{2} \mathrm{O}_{2}$ in the microaerobic milieu, but in this case the decreased activity of catalase is a probable explanation for its reduced ability to handle the toxic effects. This agrees with our previous findings that catalase plays a very important role for LVS in protection against $\mathrm{H}_{2} \mathrm{O}_{2}$ [21].

The present study confirms previous findings that MglA plays an important role for the adaptation to oxidative stress in $F$. tularensis LVS and, moreover, we demonstrate that the role of MglA is most critical during growth in an aerobic milieu, whereas its importance is less obvious in an oxygen-restricted milieu. Therefore, we hypothesize that MglA is of special importance for the bacterium to survive in oxygen-rich foci.

\section{Conclusions}

We made the important observation that a major factor for the diminished growth of $\Delta m g l A$ appeared to be its impaired adaptation to a normal oxygen environment since its growth was normalized under microaerobic conditions. The growth defect of the mutant reflects the important role of MglA for the antioxidant defense and the data show there are MglA-independent mechanisms that transcriptionally regulate the $f_{s} l$ operon, $f e o B$, or katG. In addition, our data indicate that LVS copes with oxidative stress by concomitantly upregulating detoxifying enzymes and downregulating iron sequestration.

\section{Correspondence}

Anders Sjöstedt, Department of Clinical Microbiology, Umeå University, SE-901 85 Umeå

\section{Acknowledgements}

Grant support was also obtained from the Swedish Medical Research Council (2010-9485) and the Medical Faculty, Umeå University, Umeå, Sweden. The work was performed in part at the Umeå Centre for Microbial Research (UCMR).

\section{Authors' contributions}

$\mathrm{MH}$ carried out the growth experiments, OxyBlot assay, gene expression studies, CAS-plate assay, $\mathrm{H}_{2} \mathrm{O}_{2}$ susceptibility test, participated in the design of experiments, analysis of collected data and drafting of the manuscript. $\mathrm{HL}$ carried out the catalase assay, ferrozine assay and statistical analysis, conceived of, and designed the experiments, analyzed the collected data and drafted the manuscript. AS conceived of the study, participated in its design and coordination, and drafted the manuscript. All authors read and approved the final manuscript.

\section{Competing interests}

The authors declare that they have no competing interests.

Received: 21 April 2011 Accepted: 21 January 2012

Published: 21 January 2012

\section{References}

1. Sjöstedt A: Tularemia: history, epidemiology, pathogen physiology, and clinical manifestations. Ann N Y Acad Sci 2007, 1105:1-29.

2. Tärnvik A, Berglund L: Tularaemia. Eur Respir J 2003, 21(2):361-373.

3. Dennis DT, Inglesby TV, Henderson DA, Bartlett JG, Ascher MS, Eitzen E, Fine AD, Friedlander AM, Hauer J, Layton $M$, et al: Tularemia as a biological weapon: medical and public health management. Jama 2001, 285:2763-2773.

4. Conlan JW: Vaccines against Francisella tularensis-past, present and future. Expert Rev Vaccines 2004, 3:307-314.

5. Sjöstedt A: Intracellular survival mechanisms of Francisella tularensis, a stealth pathogen. Microbes Infect 2006, 8:561-567.

6. Lindgren H, Golovliov I, Baranov V, Ernst RK, Telepnev M, Sjöstedt A: Factors affecting the escape of Francisella tularensis from the phagolysosome. J Med Microbiol 2004, 53:953-958.

7. Bönquist L, Lindgren $H$, Golovliov I, Guina T, Sjöstedt A: The MglA and Igl proteins contribute to the modulation of Francisella tularensis LVScontaining phagosomes in murine macrophages. Infect Immun 2008, 76:3502-3510.

8. Charity JC, Costante-Hamm MM, Balon EL, Boyd DH, Rubin EJ, Dove SL: Twin RNA polymerase-associated proteins control virulence gene expression in Francisella tularensis. PLoS Pathog 2007, 3:e84.

9. Brotcke A, Weiss DS, Kim CC, Chain P, Malfatti S, Garcia E, Monack DM: Identification of MglA-regulated genes reveals novel virulence factors in Francisella tularensis. Infect Immun 2006, 74:6642-6655.

10. Guina T, Radulovic D, Bahrami AJ, Bolton DL, Rohmer L, Jones-Isaac KA, Chen J, Gallagher LA, Gallis B, Ryu S, et al: MglA regulates Francisella tularensis subsp. novicida (Francisella novicida) response to starvation and oxidative stress. J Bacteriol 2007, 189(18):6580-6586.

11. Schaible UE, Kaufmann SH: Iron and microbial infection. Nat Rev Microbiol 2004, 2:946-953.

12. Wandersman C, Delepelaire P: Bacterial iron sources: from siderophores to hemophores. Annu Rev Microbiol 2004, 58:611-647.

13. Deng K, Blick RJ, Liu W, Hansen EJ: Identification of Francisella tularensis genes affected by iron limitation. Infect Immun 2006, 74:4224-4236.

14. Sullivan JT, Jeffery EF, Shannon JD, Ramakrishnan G: Characterization of the siderophore of Francisella tularensis and role of $f s / A$ in siderophore production. J Bacteriol 2006, 188(11):3785-3795.

15. Ramakrishnan G, Meeker A, Dragulev B: fsIE is necessary for siderophoremediated iron acquisition in Francisella tularensis Schu S4. J Bacteriol 2008, 190:5353-5361.

16. Buchan BW, McLendon MK, Jones BD: Identification of differentially regulated Francisella tularensis genes by use of a newly developed Tn5- 
based transposon delivery system. Appl Environ Microbiol 2008, 74(9):2637-2645.

17. Winterbourn CC: Toxicity of iron and hydrogen peroxide: the Fenton reaction. Toxicol Lett 1995, 82-83:969-974.

18. Zheng M, Doan B, Schneider TD, Storz G: OxyR and SoxRS regulation of fur. J Bacteriol 1999, 181(15):4639-4643.

19. Golovliov I, Sjöstedt A, Mokrievich A, Pavlov V: A method for allelic replacement in Francisella tularensis. FEMS Microbiol Lett 2003, 222(2):273-280.

20. Lindgren H, Honn M, Golovlev I, Kadzhaev K, Conlan W, Sjöstedt A: The 58$\mathrm{kDa}$ major virulence factor of Francisella tularensis is required for efficient utilization of iron. Infect Immun 2009, 77:4429-4436.

21. Lindgren H, Shen H, Zingmark C, Golovliov I, Conlan W, Sjöstedt A: Resistance of Francisella tularensis strains against reactive nitrogen and oxygen species with special reference to the role of KatG. Infect Immun 2007, 75:1303-1309.

22. Lindgren H, Honn M, Salomonsson E, Kuoppa K, Forsberg A, Sjöstedt A: Iron content differs between Francisella tularensis subspecies tularensis and subspecies holarctica strains and correlates to their susceptibility to H2O2-induced killing. Infect Immun 2011, 79:1218-1224.

23. Bröms JE, Lavander M, Sjöstedt A: A conserved alpha-helix essential for a type VI secretion-like system of Francisella tularensis. J Bacteriol 2009, 191:2431-2446.

24. Lauriano CM, Barker JR, Yoon SS, Nano FE, Arulanandam BP, Hassett DJ, Klose KE: MgIA regulates transcription of virulence factors necessary for Francisella tularensis intraamoebae and intramacrophage survival. Proc Natl Acad Sci USA 2004, 101:4246-4249.

25. Gavrilin MA, Mitra S, Seshadri S, Nateri J, Berhe F, Hall MW, Wewers MD: Pyrin critical to macrophage IL-1 beta response to Francisella challenge. J Immunol 2009, 182(12):7982-7989.

26. Riemer J, Hoepken HH, Czerwinska H, Robinson SR, Dringen R: Colorimetric ferrozine-based assay for the quantitation of iron in cultured cells. Anal Biochem 2004, 331:370-375.

27. Hantke K: Iron and metal regulation in bacteria. Curr Opin Microbiol 2001, 4:172-177.

28. Kiss K, Liu W, Huntley JF, Norgard MV, Hansen EJ: Characterization of fig operon mutants of Francisella novicida U112. FEMS Microbiol Lett 2008, 285:270-277.

29. Masip L, Veeravalli K, Georgiou G: The many faces of glutathione in bacteria. Antioxid Redox Signal 2006, 8:753-762.

doi:10.1186/1471-2180-12-14

Cite this article as: Honn et al:: The role of MglA for adaptation to

oxidative stress of Francisella tularensis LVS. BMC Microbiology 2012 12:14.

\section{Submit your next manuscript to BioMed Central and take full advantage of:}

- Convenient online submission

- Thorough peer review

- No space constraints or color figure charges

- Immediate publication on acceptance

- Inclusion in PubMed, CAS, Scopus and Google Scholar

- Research which is freely available for redistribution

Submit your manuscript at www.biomedcentral.com/submit 